Article

\title{
North American Engineering, Procurement, Fabrication and Construction Worker Safety Climate Perception Affected by Job Position
}

\author{
Clint Pinion ${ }^{1, *(\mathbb{B})}$, James Klyza Jr. ${ }^{1}$, Shelley Brewer ${ }^{2}$ and David Douphrate ${ }^{3}$ \\ 1 Department of Environmental Health Science, College of Health Science, Eastern Kentucky University, \\ Dizney 215, 521 Lancaster Avenue, Richmond, KY 40475, USA; james.klyza@eku.edu \\ 2 Plycem USA, LLC, 1001 West Industrial Drive, Terre Haute, IN 47802, USA; sbrewer@elementia.com \\ 3 Department of Epidemiology, Human Genetics and Environmental Science, School of Public Health, \\ The University of Texas Health Science Center at Houston, 7411 John Smith Drive, Suite 1124, \\ San Antonio, TX 78229, USA; david.i.douphrate@uth.tmc.edu \\ * Correspondence: clint.pinion@eku.edu; Tel.: +1-859-622-6330; Fax: +1-859-622-1939
}

Received: 19 January 2018; Accepted: 28 March 2018; Published: 4 April 2018

\begin{abstract}
Understanding and implementing the results of Safety Climate surveys can assist in decreasing occupational injuries and illnesses. The following article presents findings of a cross-sectional study that assessed the relationship between safety climate perceptions and job position among engineering, procurement, fabrication and construction (EPFC) employees using a 15-item survey. Descriptive statistics (means and frequencies) and an ANACOVA (analysis of covariance) were performed on a saturated model. The study had a $62 \%$ response rate. Results indicate a statistically significant in mean safety climate scores between job position among EPFC employees when controlling for years in industry and location type (i.e., construction versus fabrication) $[\mathrm{F}(9,603)=5.28, p<0.0001$, adjusted R-square $=0.07]$. Employee perception of safety climate differed based on the employee's job position (i.e., laborer, foreman, etc.). Project management reported the highest safety climate scores (0.91), followed by supervisors (0.86), technical support employees and foremen (0.84) and laborers (0.81).
\end{abstract}

Keywords: EPFC; safety climate; job position; worksite subcultures

\section{Introduction}

\subsection{Background}

Employees in the construction field typically have several employers per year and often experience changes in their work environment as projects progress to completion [1]. The work processes, equipment, tools and materials used on construction projects are more hazardous than other industries [2]. The dynamic nature of construction combined with hazardous work conditions increases the likelihood that a construction employee may experience an occupational injury or illness. Occupational injury and illness prevalence is higher among construction workers than in other industries [3]. In 2015, 985 fatalities were reported in the U.S. construction industry [4].

Historically, research examining numbers of work-related injuries, illnesses and fatalities focused on lagging indicators of safety performance, such as injury or fatality statistics [5,6]. More recently the focus of work-related safety research has shifted from lagging to leading indicators. Leading indicators, which can include workplace conditions, events or measures, are upstream indicators of future incidents. Leading indicators examine procedures, policies and programs at an industrial site [6] that provide insight into the site's safety climate. Safety climate is a collective employee perception 
of safety in their work environment. The shift of focus from lagging to leading indicators is due to more awareness of the impact human, managerial and organizational factors have on occupational incidents [5]. Future occupational incidents can be prevented if organizational leadership understands the effect that varying levels of worker safety climate perceptions can have on employee performance.

\subsection{Literature Review}

Introduced in 1980, safety climate was defined by Zohar [7] as, "molar perceptions that employees share about their work environments." Zohar [7] initially suggested that dimensions of safety climate included the following: management commitment to safety, safety training emphasis, communication, good housekeeping and environmental control, stability of workforce and safety promotion. Zohar [7] reported a correlation between safety program effectiveness and level of safety climate. Employee's perceptions of management attitudes about safety and the relevance of production safety processes were the most important dimensions in determining safety climate [7].

Since safety climate was first conceptualized by Zohar [7], numerous studies have attempted to further define safety climate. Each definition includes characterizations of employee perceptions of management, organizational policies, work environments and work practices [8]. Ultimately, safety climate provides a picture of employees' perception of safety [8-10], which depends on personal values and how safety is believed to affect their well-being $[9,11]$. If an employee's well-being appears to be affected, the employee may perceive safety as a priority. On the contrary, safety may not be a priority if the employee perceives safety as not affecting their well-being [11].

Safety climate initiates with individual employee perception but is then shared among co-workers through socialization and observation of supervisors [12]. An employee begins to understand safety expectations through interacting with co-workers and understanding workplace safety procedures, practices and events [12]. In other words, an employee internalizes workplace safety norms (i.e., requirements) through socialization [13].

Leadership is considered an antecedent to safety climate [12]. Through supervisory actions and communication, employees begin to form a perception of 'what is important' to their work organization. Employees will perceive safety as a priority if supervisors communicate the importance of safety behaviors, practices and procedures.

Safety-related behaviors are influenced by front-line supervisors' leadership styles [14]. Supervisors with strong safety leadership motivate employees to consider group safety goals as opposed to self-interest [14,15]. Supervisors will also express the importance of safety through serving as active role models for employees [14]. Safety-enhancing behaviors increase when supervisors exhibit safe work behaviors. Employees will perceive safety as unimportant if supervisors exhibit unsafe work behaviors [14].

Safety performance is affected by the value that an individual assigns to his or her workplace safety behavior. Personal value will affect an individual's safety motivation, which in turn affects safety performance; safety motivation refers to "an individual's willingness to exert effort to enact safety behaviors and the valence associated with those behaviors" [11]. A positive safety climate perception can induce safety practice and procedure compliance. Individuals working in groups with positive safety climate report increased safety motivation. Increased safety motivation is associated with positive changes in safety citizenship. Work safety is improved when employees perceive safety as being important [11].

Research indicates safety climate perceptions will vary between subcultures existing on a worksite (i.e., laborers have similar safety climate perceptions). Safety climate perception variance among subcultures on a single worksite may be attributed acculturation of employees during apprenticeships and work with previous employers. It is imperative to note the dynamic nature and short tenure of a EPFC job. Individuals from many companies may come together over the course of months to a few years to complete a EPFC project. Varying safety climate perceptions may lead to disparities in communication, safety performance and safety citizenship between subcultures [16]. 
Studies measuring safety attitudes (i.e., safety climate perceptions) among subcultures have been conducted in the nuclear [16-18], hospital [19], road construction [20] and manufacturing [21] settings. Lee [17] reported significant differences in safety climate perceptions between different job positions. Craft, supervisors and frontline managers had more negative attitudes regarding worksite risk than senior managers. Safety professionals reported negative perceptions of safety compared to all other job position types. Harvey and colleagues identified the importance of recognizing varying safety climate perceptions between subcultures; Safety incidents due to increased risk-taking behavior and miscommunication were linked to differing safety attitudes among two subcultures (i.e., management and industrial workers) [18]. Findley et al. [16] report significant differences in safety climate scores between job position types; specifically, foreman had the lowest safety climate perception scores, followed by craft workers, technical support, supervisors, staff and senior managers. Singer et al. [19] noted better safety climate perception among frontline personnel compared to senior management. Positive safety climate perception among frontline personnel predicted decreased patient safety indicator rates.

Noticeably absent from literature are articles addressing safety climate perception differences between subcultures on large construction projects aimed at building energy infrastructure facilities. This cross-sectional study used a survey to capture employee perception of safety climate within the engineering, procurement, fabrication and construction (EPFC) industry. The study objective was to assess the relationship between employee safety climate perception and job position. Job position refers to each employee's work title (i.e., laborer, foreman, supervisor, technical staff and project management). We hypothesized that employee safety climate perceptions would differ based on job position.

\section{Methods}

\subsection{Instrument}

This exploratory cross-sectional study was part of a larger study detailed in Pinion et al. [22]. This study used a 15-item survey to examine employee perception of workplace safety climate. The survey measured safety climate perceptions of participants with 7 questions adapted from Jorgensen and colleagues [23] as shown in Table 1. Wu and colleagues [24] provide guidance on four core dimensions of construction safety climate. Questions four and seven used in the study instrument relate to the core dimension of safety priority. Safety priority refers to employee perception of safety compared to other organizational goals [24]. Questions two and six used in the study instrument pertain to the core dimension of safety supervision, training and communication. Safety supervision, training and communication specifically highlight common indicators of a good safety management system [24]. Questions one and five used in the study instrument pertain to safety rules and procedures. $\mathrm{Wu}$ and colleagues define this dimension as relating to: meeting or violating company safety rules; employee perception of company safety procedures; and employee risk-taking behaviors [24]. Question three used in the study instrument pertains to the core dimension of safety involvement, which highlights the importance safety involvement from all employee levels within a company.

Table 1. Safety Climate Survey Questions.

\footnotetext{
1. New employees quickly learn that they are expected to follow good safety practices.

2. Employees are told when they do not follow good safety practices.

3. Employees and management work together to ensure the safest possible working conditions.

4. The safety of employees is a big priority with management where you work.

5. No significant compromises or shortcuts are taken when employee safety is at stake.

6. Employees feel free to report safety violations where you work.

7. Safety remains a priority even when the job runs behind schedule.
} 
The reliability and psychometric properties of the survey instrument have not been tested. A piloting of the survey was conducted at a fabrication shop in Texas. Corrections based on the pilot test were made. Study participants could respond to each survey question with the following responses: (a) strongly disagree; (b) disagree; (c) neutral; (d) agree and (e) strongly agree. The survey included the following demographic information: (a) age; (b) sex; (c) education level; (d) region of origin; (e) job position; (f) years worked in construction industry; (g) years worked with company and (h) location. Age was divided age into four categories: (1) $\leq 24$; (2) $25-34$; (3) 35-49 and (4) $\geq 50$. Five categories for education were included: (1) some high school; (2) high school or GED diploma; (3) some college; (4) college degree and (5) graduate degree. Job positions are categorized based on the EPFC Company's hierarchal structure. Five categories were included for job position: (1) laborer/tradesperson; (2) foreman; (3) superintendent/supervisor; (4) technical support/engineering/HSE/quality and (5) construction management/project management. Region of origin options included: (1) Canada; (2) United States; (3) Central America; (4) South America; (5) Africa; (6) Western Europe; (7) Eastern Europe; (8) Asia Pacific and (9) Australia. Options for years worked in the construction industry and years worked with company both included: $(1)<1,(2) 1-5$, (3) 6-10, (4) 11-15 and (5) $\geq 16$. Location options included fabrication and construction.

\subsection{Inclusion and Exclusion Criteria}

Inclusion criteria for this study were: (1) employed with the EPFC Company; (2) able to read and comprehend the informed consent form and survey that is written in English; (3) sign an informed consent form; and (4) complete all sections of the survey. Exclusion criteria for this study included: (1) declining to participate in the study (2) declining to sign an informed consent form and (3) unable to read and comprehend the informed consent form and survey which are written in English.

\subsection{Recruitment and Consent}

EPFC Company employees, from seven sites, meeting the inclusion criteria were invited to participate in this study. The seven sites were located in the following areas: Texas $(n=3)$, Iowa $(n=1)$, Alberta $(n=2)$ and West Virginia $(n=1)$. The industrial activity of the EPFC sites were as follows: one (1) steel plate fabrication shop, two (2) modular fabrication/construction sites and four (4) active construction sites constructing steel plate containment vessels and pipe racks. The employees were recruited during regularly scheduled company safety meetings. During these meetings, supervisors were asked to not be present as the principal investigator explained the study purpose. Employees were reminded that they had the option of not participating in the study. Individuals opting not to participate were allowed to remain at the meeting, ensuring the anonymity of each participant's decision. EPFC employees choosing to participate were given an informed consent form to read and sign. The employees were administered the survey in paper format upon completion of the informed consent form.

\subsection{Analysis}

To assess differences in safety climate scores between job position, a safety climate score (SCS) was calculated for each participant. Participants rated each question listed in Table 1 between 1 and 5 . The highest point total resulting in a total of 35 possible points. The safety climate score was a summation of scores assigned to each item, divided by the total points possible, expressed as a percent. Descriptive statistics (means and frequencies) and an ANACOVA (analysis of covariance) were performed on a saturated model. The backwards elimination method was then used to reach the most parsimonious model with an a priori alpha of $p<0.05$. In this process, the covariate with the highest $p$-value is removed from the model. The modified model is then rerun for significance of the covariates. The same elimination method was repeated until the remaining covariates are statistically significant. 
The Least Squares Difference (LSD), Tukey's Studentized Range (HSD) and Scheffe's Test were simultaneously used with the ANACOVA to better ascertain the differences in pairwise comparisons of the categorical covariate (job position). A power analysis was performed to determine how well the model controlled for type II errors (false negatives). In addition, the model assumptions, including normality of residuals, collinearity and homogeneity of variance, were tested. Power was estimated to be greater than $99 \%$. Bartlett's test was used to test homogeneity of the variance for the categorical variable (job position). Bartlett's test can be inaccurate if distribution is non-normal [20].

The initial saturated model was as follows:

$$
\begin{gathered}
\mathrm{Y}=\beta_{0}+\beta_{1}(\text { JOB POSITION })+\beta_{2}(\text { AGE-CATEGORICAL })+\beta_{3}(\text { GENDER })+ \\
\beta_{4}(\text { EDUCATION })+\beta_{5}(\text { LOCATION })+\beta_{6}(\text { YEARS IN INDUSTRY })+ \\
\beta_{7}(\text { YEARS WITH EMPLOYER })+\varepsilon
\end{gathered}
$$

where: $\mathrm{Y}=$ Safety Climate Score, JOB POSITION = Job position of Study Participant, AGE-CATEGORICAL = Age of Study Participant, GENDER = Self-identified gender of Study Participant, EDUCATION $=$ Highest level of education completed by Study Participant, LOCATION = Type of work location, YEARS IN INDUSTRY = years working in EPFC industry and YEARS WITH EMPLOYER = Number of years Study Participant worked with EPFC company.

The final model was as follows: $Y=\beta_{0}+\beta_{1}$ (JOB POSITION) $+\beta_{2}$ (YEARS IN INDUSTRY) $+\beta_{3}$ $($ LOCATION $)+$ E. Where: $Y=$ Safety Climate Score, JOB POSITION = Job positon of Study Participant, YEARS IN INDUSTRY = years working in EPFC industry and LOCATION = type of work location.

\section{Results}

\subsection{Response Rate}

981 EPFC employees at seven different industrial sites were invited to participate in this original study (Pinion et al., 2017). 613 of the 981 surveys were completed for a response rate of $62 \%$. The completed 613 surveys were included in the analysis for this study.

\subsection{Participant Demographics}

An overview of participant demographics is provided in Table 2. The participants were predominantly male $(n=578,95 \%)$ and were from the United States $(n=441,72 \%)$ and Canada $(n=132,22 \%)$ and had completed a high school diploma or greater $(n=559,91 \%)$. Only seventeen percent of participants completed a college degree $(n=105)$. The participant pool was predominantly comprised of laborers or tradespeople $(n=443,72 \%)$. The majority of participants had worked in the construction industry for more than six years $(n=463,76 \%)$. However, the majority of participants had worked for the EPFC company for less than 5 years $(n=446,73 \%)$.

Table 2. Participant Demographics.

\begin{tabular}{cccc}
\hline Demographic Category & $n$ & Safety Climate Score Mean & Standard Deviation \\
\hline Age & & & \\
$<24$ & 67 & 0.82 & 0.09 \\
$25-34$ & 180 & 0.82 & 0.12 \\
$35-49$ & 225 & 0.82 & 0.11 \\
$>50$ & 141 & 0.83 & 0.13 \\
\hline Sex & & & \\
Male & 578 & 0.82 & 0.12 \\
Female & 35 & 0.85 & 0.09 \\
\hline Region of Origin & & & \\
Canada & 132 & 0.81 & 0.13 \\
United States & 441 & 0.83 & 0.11 \\
Central America & 13 & 0.78 & 0.14 \\
\hline
\end{tabular}


Table 2. Cont.

\begin{tabular}{|c|c|c|c|}
\hline Demographic Category & $n$ & Safety Climate Score Mean & Standard Deviation \\
\hline South America & 7 & 0.81 & 0.05 \\
\hline Africa & 1 & 1.00 & 000 \\
\hline Western Europe & 0 & 000 & 000 \\
\hline Eastern Europe & 1 & 0.80 & 000 \\
\hline Asian pacific & 17 & 0.87 & 0.11 \\
\hline Australia & 1 & 0.69 & 000 \\
\hline Mexico & 0 & 000 & 000 \\
\hline \multicolumn{4}{|l|}{ Education Level } \\
\hline Some High School & 54 & 0.84 & 0.09 \\
\hline High School or Equivalency Diploma & 274 & 0.82 & 0.11 \\
\hline Some College & 180 & 0.82 & 0.12 \\
\hline College Degree & 97 & 0.81 & 0.13 \\
\hline Graduate Degree & 8 & 0.90 & 0.08 \\
\hline \multicolumn{4}{|l|}{ Job Position } \\
\hline Laborer & 443 & 0.81 & 0.12 \\
\hline Foreman & 70 & 0.84 & 0.11 \\
\hline Supervisor & 27 & 0.86 & 0.08 \\
\hline Technical Support (Engineers, HSE, Quality) & 60 & 0.84 & 0.11 \\
\hline Project Management & 13 & 0.91 & 0.07 \\
\hline \multicolumn{4}{|l|}{ Years worked in Industry } \\
\hline$<1$ & 51 & 0.84 & 0.09 \\
\hline $1-5$ & 99 & 0.85 & 0.09 \\
\hline $6-10$ & 131 & 0.81 & 0.13 \\
\hline $11-15$ & 107 & 0.81 & 0.13 \\
\hline$\geq 16$ & 225 & 0.83 & 0.12 \\
\hline \multicolumn{4}{|l|}{ Years worked for Company } \\
\hline$<1$ & 255 & 0.82 & 0.11 \\
\hline $1-5$ & 191 & 0.83 & 0.11 \\
\hline $6-10$ & 77 & 0.80 & 0.14 \\
\hline $11-15$ & 31 & 0.81 & 0.14 \\
\hline$\geq 16$ & 59 & 0.84 & 0.11 \\
\hline \multicolumn{4}{|l|}{ Location Type } \\
\hline Fabrication & 277 & .80 & 0.12 \\
\hline Construction & 336 & 0.84 & 0.11 \\
\hline
\end{tabular}

\subsection{Overall SCS Perceptions}

An unstratified mean score was calculated for the discrete variable. The mean Safety Climate score (SCS) for all participants was $0.82(\mathrm{SD}=0.12)$.

\subsection{Study Results}

As Table 3 illustrates, the final ANACOVA results showed that differences in safety climate mean sores (SCS) were statistically significant between job positions when controlling for years in industry and location, $\mathrm{F}(9,603)=5.28, p<0.0001$. The adjusted R-square was 0.07 .

Table 3. ANACOVA Final Model: The Generalized Linear Model (GLM) Procedure.

\begin{tabular}{|c|c|c|c|c|c|}
\hline Source & DF & Sum of Squares & Mean Square & $F$ Value & $\operatorname{Pr}>F$ \\
\hline Model & 9 & 0.61 & 0.07 & 5.28 & $<0.0001$ \\
\hline Error & 603 & 7.74 & 0.01 & - & - \\
\hline Corrected Total & 612 & 08.63 & - & - & - \\
\hline R-Square & Coeff Var & Root MSE & SCS Mean & - & - \\
\hline 0.07 & 13.76 & 0.11 & 0.82 & - & - \\
\hline Source & DF & Type I SS & Mean Square & F Value & $\operatorname{Pr}>F$ \\
\hline Job position & 4 & 0.22 & 0.06 & 4.32 & 0.0019 \\
\hline Years working in industry & 4 & 0.14 & 0.04 & 2.80 & 0.0252 \\
\hline Location & 1 & 0.24 & 0.24 & 19.06 & $<0.0001$ \\
\hline
\end{tabular}


Table 4 shows the difference between means and significance of pairwise comparisons for the categorical variable job position. Comparisons that were significant are denoted with asterisks. As Table 4 indicates, difference in mean safety climate scores were significant between laborers and three categories (i.e., project management, supervisors and foremen).

Table 4. $t$ Tests: Least Significant Difference (LSD) for Safety Climate Score (SCS) and job position.

\begin{tabular}{ccccc}
\hline Job Position Comparison & Difference between Means & \multicolumn{3}{c}{ 95\% Confidence Limits } \\
\hline Project & 0.094 & 0.032 & 0.157 & $* * *$ \\
Management-Laborer & 0.045 & 0.001 & 0.089 & $* * *$ \\
Supervisor-Laborer & 0.031 & 0.003 & 0.060 & $* * *$ \\
Foreman-Laborer & $* * *$ Comparisons significant at the 0.05 level.
\end{tabular}

Table 5 shows the difference between means and significance of pairwise comparisons for the categorical variable "years in industry." Comparisons that were significant are denoted with asterisks. As Table 5 indicates, difference in mean safety climate scores were significant between employees working 1-5 years in the EPFC industry and two categories (i.e., 6-10 years and 11-15 years).

Table 5. $t$ Tests: Least Significant Difference (LSD) for SCS and years in industry.

\begin{tabular}{ccccc}
\hline Years in Industry Comparison & Difference between Means & \multicolumn{3}{c}{ 95\% Confidence Limits } \\
\hline 1 TO 5-6 TO 10 & 0.035 & 0.005 & 0.064 & $* * *$ \\
1 TO 5-11 TO 15 & 0.042 & 0.011 & 0.073 & $* * *$ \\
\hline \multicolumn{5}{c}{ *** Comparisons significant at the 0.05 level. }
\end{tabular}

Table 6 shows the difference between means and significance of pairwise comparisons for the categorical variable location. Comparisons with unlike letters for $t$ Grouping were significantly different. As Table 6 indicates, difference in mean safety climate scores were significant between fabrication and construction employees. Construction employees had an average safety climate score of 0.84 ; Fabrication employees had an average safety climate score of 0.80 .

Table 6. $t$ Tests: Least Significant Difference (LSD) for SCS and location.

\begin{tabular}{cccc}
\hline Alpha & 0.05 & - & - \\
Error Degrees of Freedom & 603 & - & - \\
Error Mean Square & 0.01 & - & - \\
Critical Value of $\mathrm{t}$ & 1.96 & - & - \\
Harmonic Mean of Cell Sizes & 304 & - & - \\
\hline $\boldsymbol{t}$ Grouping & Mean & $\mathbf{N}$ & Location \\
\hline A & 0.84 & 336 & Construction \\
B & 0.80 & 277 & Fabrication \\
\hline
\end{tabular}

Note: Means with different letter for $t$ Grouping are significantly different.

\section{Discussion}

\subsection{Study Outcomes}

The study's purpose was to examine differences in safety climate scores between job positions among employees working for an EPFC company. The EPFC company fabricated and constructed large energy infrastructure facilities. Differences in safety climate sores (SCS) between job positions was found when controlling for years in industry and location type (i.e., construction versus fabrication sites), $F(9,603)=5.28, p<0.0001$. Thus, employee safety climate scores differed based on the employee's job position (i.e., laborer, foreman, etc.). Laborers had lower safety climate scores $(0.81)$ 
compared to project managers, supervisors and foreman. These findings are supported by Harvey and colleagues [18], Gittleman and colleagues [25] and Findley and colleagues [16]. Harvey et al. [18] and Findley et al. [16] found safety climate perception scores to differ between two distinct subcultures in the nuclear industry. Findley et al. [16] found differences in safety climate based on job position in the nuclear industry. Gittleman and colleagues [25] reported more positive safety climate perceptions compared to workers. Similar to this study, Findley and Colleagues [16] reported higher safety climate perception among senior management compared to all other job position types.

Safety climate perceptions often are not homogenous across an organization [26]. Workplace conditions and work activities impact site safety climate research more than demographic variables. Situational conditions such as job demands and work stressors and work activities would be expected to affect safety climate, because safety climate focuses on employees' perception of safety procedures, practices and behaviors at their worksite [12]. Important to note, safety climate perception differences between job position types or subcultures can lead to increased personal safety risk, increased safety incidents and inter-organizational conflict [16]. Thus, understanding why safety climate differs between subcultures enhances a safety professional's ability to craft and implement targeted safety programming (e.g., campaigns, trainings, etc.).

An employee's safety responsibility and thus safety citizenship expectations are linked to job position. Laborers are often the target of safety training, programs and initiatives. Individuals in leadership positions (e.g., project managers, supervisors and foreman) manage safety programming. Safety experiences would differ based on job position, thus causing varying perceptions of safety climate. Literature indicates more positive safety climate perceptions among individuals in leadership positions [26,27], which was supported by this study. Employees in supervisor roles are expected to serve as safety role models and are often tasked with administering safety programs and encouraging safety citizenship among their direct reports. Intuitively, it is expected that individuals implementing or managing safety programming would have more positive safety climate, as poor safety climate would be a reflection on their own abilities to keep their direct reports safe.

Safety climate score means differed in the EPFC Company by location type (i.e., fabrication or construction). Employees selecting construction as location type had higher safety climate scores. Fabrication employees work in a less dynamic environment; with many employees performing the same job tasks each day using the same materials and equipment. Construction employees work in a dynamic setting, often experiencing changes of work environment, equipment, materials and management [3]. The difference in safety climate scores between fabrication and construction employees in the EPFC Company may reflect variances in implementing the company's workplace safety procedures and programs. Thus, the safety leadership style may differ between fabrication and construction sites leading to different safety socialization experiences.

A significant difference in mean safety climate scores was found between employees working 1-5 years in the EPFC industry and two categories (i.e., 6-10 years and 11-15 years). Research indicates demographic variables such as gender, age, education level, work experience in the industry do not influence participant's perceptions of safety climate [28]. Further, Choudhry and colleagues [29] suggest workers with more experience will have a more favorable outlook on safety comparatively to employees with shorter tenure. The data from this study suggests employees with five or less years of work experience in the construction industry will have higher safety climate scores. Choudhry et al. [29] notes differences in safety perceptions based on years worked in the construction industry may be related to the value of family. Employees having worked longer in the construction industry are more likely to have families for whom they need to provide and thus feel the need to protect themselves from injury or fatalities

Safety Climate Results and Leadership

Management can impact safety climate perceptions through leadership style. In fact, Yule [8] identified management and leadership style as important factors in evaluating site safety climate. 
Employees observe supervisors' attitudes and behaviors toward safety, production and other organizational issues; these observations help form each employee's perception of safety's importance within the organization [5]. Three questions $(4,5$ and 7$)$ in the study survey specifically reviewed employee perceptions of supervisors' attitudes and beliefs toward production and other organizational issues as they pertained to safety. Participants overwhelmingly agreed or strongly agreed that: employee safety is a big priority with management within their organization; no significant compromises or shortcuts are taken when employee safety is at stake; and safety remains a priority even when the job runs behind schedule.

The majority of respondents (\%) agreed or strongly agreed that new employees quickly learned that they were expected to follow good safety practices. New employees understanding expectations can be attributed to peer socialization and positive role modeling by supervisors. Supervisory role modeling is one of four transformational leadership practices. The remaining three are: inspiring employees to commit to a common goal, understanding the individual needs of each employee and intellectually engaging employees in a desired process [14]. In fact, safety enhancing behaviors increase when supervisors exhibit safe work behaviors (i.e., model desired safety behaviors) [14]. Employees will perceive safety as unimportant if supervisors constantly exhibit unsafe work behaviors [14].

With the exception of approximately ten percent of respondents, the majority of EPFC employees agreed or strongly agreed that employees are told when they do not follow good safety practices. Participants also stated that employees and management within their organization work together to ensure the safest possible working conditions. The survey questions highlight aspects of communication and collaboration. Transformational leadership involves a leader setting goals and working with employees and encouraging employee performance. Feedback to employees occurs based on supervisor observations of the employee's performance. The feedback is meant to promote both individual and organizational change. Feedback is meant to either improve or sustain employee performance [14]. In organizations with positive safety climates, supervisors work closely with employees to set goals and encourage open dialogue regarding safety to ensure adequate communication of priority safety information. Encouraging open safety dialogue empowers employees, which is evident from participant responses to question six of the study survey. The majority of participants agreed or strongly agreed that employees within their organization feel free to report safety violations.

\subsection{Limitations}

The authors used a self-reporting survey tool to measure safety climate. This study was also limited by the cross-sectional approach of survey administration, with administration occurring one time per site. The authors recommend that future studies administer the survey multiple times at each site for safety climate score comparisons. It should be noted that self-reporting survey tools can be useful in ascertaining workplace safety climate and employees' perception of management commitment to safety. The study was only administered within one company; thus, organizational issues affecting safety climate perceptions could alter safety climate scores.

\subsection{Strengths}

The author's findings regarding the relationship between job position and safety climate perception are consistent with existing studies but add to the literature as prior studies were not conducted in EPFC companies that build large energy infrastructure facilities. One study [25] did have similar findings to this study but was limited in scope, as only one study site was used. Thus, this study strengthens literature focusing on the relationship between safety climate perceptions and job position in the EPFC industry. Tailoring safety programming by job position or worksite subcultures is supported by this study. Varying layers of an organization should be targeted differently for safety programming and campaigns aimed at preventing occupational injuries and illnesses. 


\section{Conclusions}

The study findings highlight the importance of job position in both safety climate perception and safety programming in the construction of large energy infrastructure facilities. Laborers will have different safety climate perceptions than individuals in leadership roles (e.g., project manager, supervisors and foremen). Thus, safety professionals should design safety programming that targets each employee based on their role in the organization. Project managers, supervisors and foremen should be targeted for their role in socializing new employees in a company's safety culture. These individuals should be knowledgeable of company safety policies and procedures and should work to ensure their direct reports are in conformance.

The significant difference of mean safety climate scores between employees working $1-5$ years and two categories (i.e., 6-10 years and 11-15 years) was not expected per literature. Further, employees with less than 5 years of industry experience had higher scores than those with greater than 6 years of experience. This finding could suggest that seasoned construction employees be targeted by safety programming to ensure ongoing safety participation and engagement, to minimize the risk of employee complacency.

Author Contributions: Clint Pinion conceived the idea for this manuscript. Clint Pinion and James Klyza Jr. completed the analyses for this manuscript. All authors contributed to the writing of the final manuscript.

Conflicts of Interest: There are no conflicts-of-interest to disclose.

Disclaimer Statements: There are no disclaimers to declare.

Ethics Approval: Institutional Review Board, the University of Texas Health Science Center at Houston.

\section{References}

1. Gillen, M.; Kools, S.; Sum, J.; McCall, C.; Moulden, K. Construction workers' perceptions of management safety practices: A qualitative investigation. Work 2004, 23, 245-256. [PubMed]

2. Abudayyeh, O.; Fredericks, T.; Butt, S.; Shaar, A. An investigation of management's commitment to construction safety. Int. J. Proj. Manag. 2006, 24, 167-174. [CrossRef]

3. Gilkey, D.; Lopez del Puerto, C.; Keefe, T.; Bigelow, P.; Herron, R.; Rosecrance, J.; Chen, P. Comparative analysis of safety culture perceptions among homesafe managers and workers in residential construction. J. Constr. Eng. Manag. 2011, 138, 1044-1052. [CrossRef]

4. Construction and Building Inspectors [Internet]. Place: Bureau of Labor Statistics. 2017. Available online: https: //www.bls.gov/ooh/construction-and-extraction/construction-and-building-inspectors.htm (accessed on 1 October 2017).

5. Flinn, R.; Mearns, K.; O'Connor, P.; Bryden, R. Measuring safety climate: Identifying the common features. Saf. Sci. 2000, 34, 177-192. [CrossRef]

6. Hinze, J.; Thurman, S.; Wehle, A. Leading indicators of construction performance. Saf. Sci. 2013, 51, 23-28. [CrossRef]

7. Zohar, D. Safety Climate in Industrial Organizations: Theoretical and Applied Implications. J. Appl. Psychol. 1980, 65, 96-102. [CrossRef] [PubMed]

8. Yule, S. Senior Management Influence on Safety Performance in the UK and US Energy Sectors. Ph.D. Thesis, University of Aberdeen, Aberdeen, Scotland, UK, 2003.

9. Griffin, M.; Neal, A. Perceptions of Safety at Work: A Framework for Linking Safety Climate Performance, Knowledge, and Motivation. J. Occup. Health Psychol. 2000, 5, 347-358. [CrossRef] [PubMed]

10. Huang, Y.; Ho, M.; Smith, G.; Chen, P. Safety climate and self-reported injury: Assessing the mediating role of employee safety control. Accid. Anal. Prev. 2006, 38, 425-433. [CrossRef] [PubMed]

11. Neal, A.; Griffin, M. A Study of Lagged Relationships among Safety Climate, Safety Motivation, Safety Behavior, and Accidents at the Individual and Group Levels. J. Appl. Psychol. 2006, 91, 946-953. [CrossRef] [PubMed]

12. Zohar, D. Thirty years of safety climate research: Reflections and future directions. Accid. Anal. Prev. 2010, 42, 1517-1522. [CrossRef] [PubMed] 
13. Beus, J.; Bergman, M.; Jarett, S.M.; Payne, S. The influence of organizational tenure on safety climate strength: A first look. Accid. Anal. Prev. 2010, 42, 1431-1437. [CrossRef] [PubMed]

14. Kapp, E.A. The influence of supervisor leadership practices and perceived group safety climate on employee safety performance. Saf. Sci. 2012, 50, 1119-1124. [CrossRef]

15. Lu, C.; Yang, C. Safety leadership and safety behavior in container terminal operations. Saf. Sci. 2010, 48, 123-134. [CrossRef]

16. Findley, M.; Smith, S.; Gorski, J.; O'neil, M. Safety climate differences among job positions in the nuclear decommissioning and demolition industry: Employees' self-reported safety attitudes and perceptions. Saf. Sci. 2009, 45, 875-899. [CrossRef]

17. Lee, T.R. Assessment of safety culture at a nuclear processing plant. Work Stress 1998, 12, 217-237. [CrossRef]

18. Harvey, J.; Bolam, H.; Gregory, D. How many safety cultures are there? Saf. Health Pract. 1999, 17, 9-12.

19. Singer, S.; Lin, S.; Falwell, A.; Gabba, D.; Baker, L. Relationship of safety climate and safety performance in hospitals. Health Serv. Res. 2009, 44, 399-421. [CrossRef] [PubMed]

20. Glendon, A.; Litherland, D. Safety climate factors, group differences and safety behavior in road construction. Saf. Sci. 2001, 39, 157-188. [CrossRef]

21. Cheyne, A.; Oliver, A.; Tomas, J.; Cox, S. The architecture of employee attitudes to safety in the manufacturing sector. Pers. Rev. 2002, 31, 649-670. [CrossRef]

22. Pinion, C.; Brewer, S.; Douphrate, D.; Whitehead, L.; DelliFraine, J.; Taylor, W.C.; Klyza, J. The Impact of job control on employee perception of management commitment to safety. Saf. Sci. 2017, 93, 70-75. [CrossRef]

23. Jorgensen, E.; Sokas, R.; Nickels, L.; Gao, W.; Gittleman, J. An English/Spanish Safety Climate Scale for Construction Workers. Am. J. Ind. Med. 2007, 50, 438-442. [CrossRef] [PubMed]

24. Wu, C.; Song, X.; Wang, T.; Fang, D. Core dimensions of the construction safety climate for a standardized safety-climate measurement. J. Constr. Eng. Manag. 2015, 141, 04015018. [CrossRef]

25. Gittleman, J.; Gardner, P.; Haile, E.; Sampson, J.; Cigulariov, K.; Ermann, E.; Stafford, P.; Chen, P. Case Study: CityCenter and cosmopolitan construction projgects, Las Vegas, Nevada: Lessons learned from the use of multiple sources and mixed methods in a safety needs assessment. J. Saf. Res. 2010, 41, 262-281. [CrossRef] [PubMed]

26. Marin, L.; Cifuentes, M.; Roelofs, C. Results of a community-based survey of construction safety climate for Hispanic workers. Int. J. Occup. Environ. Health 2015, 21, 223-231. [CrossRef] [PubMed]

27. Huang, Y.; Verma, S.; Chang, W.; Courtney, T.; Lombardi, D.; Brennan, M.; Perry, M. Management commitment to safety vs. employee perceived safety training and association with future injury. Accid. Anal. Prev. 2012, 47, 94-101. [CrossRef] [PubMed]

28. Fang, D.; Chen, Y.; Wong, L. Safety Climate in Construction Industry: A Case Study in Hong Kong. J. Constr. Eng. Manag. 2006, 132, 573-584. [CrossRef]

29. Choudhry, R.; Fang, D.; Lingard, H. Measuring safety climate of a construction company. J. Constr. Eng. Manag. 2009, 135, 800-899. [CrossRef]

(C) 2018 by the authors. Licensee MDPI, Basel, Switzerland. This article is an open access article distributed under the terms and conditions of the Creative Commons Attribution (CC BY) license (http://creativecommons.org/licenses/by/4.0/). 